\title{
Reduction of Radiation Exposure in Adrenal Vein Sampling: Impact of the Rapid Cortisol Assay
}

\section{Reduktion der Strahlenbelastung bei der selektiven Nebennierenvenenblutentnahme: Einfluss des Kortison-Schnelltests}

Authors

Anne Marie Augustin ${ }^{1}$, Giulia Dalla Torre ${ }^{1}$, Carmina Teresa Fuss ${ }^{2}$, Martin Fassnacht ${ }^{2}$, Thorsten Alexander Bley ${ }^{1}$, Ralph Kickuth ${ }^{1}$

Affiliations

1 Department of Diagnostic and Interventional Radiology, University Hospital Würzburg, Würzburg, Germany

2 Department of Internal Medicine I, Division of Endocrinology and Diabetes, University Hospital Würzburg, Würzburg, Germany

Key words

abdomen, adrenal gland, radiation safety, endocrine disorders, interventional procedures, venography

received 26.01.2021

accepted 05.06.2021

published online 12.08.2021

Bibliography

Fortschr Röntgenstr 2021; 193: 1392-1402

DOI 10.1055/a-1535-2566

ISSN 1438-9029

(C) 2021. Thieme. All rights reserved.

Georg Thieme Verlag KG, Rüdigerstraße 14,

70469 Stuttgart, Germany

Correspondence

Dr. Anne Marie Augustin

Institut für Diagnostische und Interventionelle Radiologie des Universitätsklinikums Würzburg, Oberdürrbacher Straße 6, 97080 Würzburg, Germany

Tel.: +49/1 60/4444333

augustin_a@ukw.de

\section{ZUSAMMENFASSUNG}

Ziel Bestimmung der Strahlenbelastung bei der selektiven Nebennierenvenenblutentnahme und deren Reduktion durch die Einführung des Kortison-Schnelltests sowie durch Modifikation des Probeentnahmeprotokolls.

Material und Methoden Im Rahmen einer retrospektiven Auswertung von Nebennierenvenenblutentnahmen zwischen August 2009 und März 2020 wurden insgesamt 151 Prozeduren analysiert und 3 Subgruppen gebildet: In Gruppe I wurde ohne Kortison-Schnelltest nach einem Protokoll vorgegangen, welches die zusätzliche Entnahme aus den Nierenvenen beinhaltete. In Gruppe II wurde nach demselben Protokoll, jedoch unter Anwendung des Kortison-Schnelltests Blut entnommen.
In Gruppe III fand ein überarbeitetes Protokoll Anwendung, bei welchem unter Beibehaltung des Kortison-Schnelltests auf die zusätzliche Entnahme aus den Nierenvenen verzichtet wurde. Primärer Endpunkt unserer Studie war die intraprozedurale Strahlenbelastung der Patienten mit Dosis-FlächenProdukt, Fluoroskopiezeit und effektiver Dosis. Sekundäre Endpunkte umfassten prozedurale Daten einschließlich des technischen Erfolgs, der Lateralisierung, der Korrelation des BMI der Patienten mit der Strahlendosis und Konkordanz der Lateralisierung mit der Schnittbildgebung. Zur Bewertung des diagnostischen Benefits einer zusätzlichen Blutabnahme aus den Nierenvenen wurde eine Korrelationsanalyse der Aldosteron-Kortison-Ratio zwischen Nebennierenvene und ipsilateraler Nierenvene durchgeführt.

Ergebnisse Das mediane Dosis-Flächen-Produkt belief sich für alle Prozeduren auf $60,01 \mathrm{~Gy}^{*} \mathrm{~cm}^{2}(5,71-789,31)$, die mediane Durchleuchtungszeit auf 14,90 min $(3,27-80,90)$ und die mediane effektive Dosis auf 12,60 mSv (1,20$165,76)$. Zwischen den Studienuntergruppen ergaben sich jeweils statistisch signifikante Unterschiede. Nach Einführung des Schnelltests zeigte sich eine Reduktion des Dosis-FlächenProdukts von 57,94\% und eine weitere Reduktion um 40,44\% nach Überarbeitung des Entnahmeprotokolls. Die Durchleuchtungszeit konnte durch Einführung des KortisonSchnelltests um 40,48\% und nach Modifikation des Protokolls um weitere $40,47 \%$ verringert werden. Eine wiederholte Abnahme führte zu einer höheren Strahlendosis (DosisFlächen-Produkt 51,31 vs. $118,11 \mathrm{~Gy}^{*} \mathrm{~cm}^{2}$, Durchleuchtungszeit 12,48 vs. $28,70 \mathrm{~min}$ ). Zwischen dem BMI der Patienten und dem Dosis-Flächen-Produkt konnte eine signifikante Korrelation nachgewiesen werden. Nach Einführung des Schnelltests zeigte sich eine sukzessive Zunahme der technischen Erfolgsraten (33,33\% in Gruppe I, 90,22\% in Gruppe II und $92,11 \%$ in Gruppe III). Die Korrelation zwischen der Aldosteron-Kortison-Ratio der Nebennierenvenen und Nierenvenen fiel nur geringgradig aus.

Schlussfolgerung Bei gleichzeitig steigenden technischen Erfolgsraten konnte die prozedurale Strahlenbelastung der selektiven Nebennierenvenenblutentnahme durch die Einführung des Kortison-Schnelltests deutlich verringert werden. Die zusätzliche Abnahme aus den Nierenvenen bot keinen diagnostischen Mehrwert in der Subtypbeurteilung des primären Hyperaldosteronismus, wobei durch eine Reduktion 
dieser Abnahmestellen eine weitere Verringerung der Strahlendosis erreicht werden konnte.

\section{Kernaussagen:}

- Der Kortison-Schnelltest führt bei der selektiven Nebennierenvenenblutentnahme zu einer signifikanten Reduktion der prozedurbezogenen Strahlenbelastung bei gleichzeitiger Erhöhung des technischen Erfolgs.

- Da die zusätzliche Blutentnahme aus den Nierenvenen keinen diagnostischen Mehrwert bietet, kann durch Überarbeitung des Entnahme-Protokolls eine weitere Reduktion der Strahlendosis erreicht werden.

- Eine wiederholte selektive Blutabnahme, technischer Misserfolg, sowie ein höherer BMI der Patientin gehen mit einer erhöhten Strahlenbelastung einher.

\section{ABSTRACT}

Purpose To determine radiation exposure associated with adrenal vein sampling and its reduction by implementing the rapid cortisol assay and modification of the sampling protocol.

Materials and Methods A single-center retrospective study of adrenal vein sampling performed between August 2009 and March 2020 revealed data from 151 procedures. Three subgroups were determined. In group I, a sampling protocol including sampling from the renal veins without the rapid cortisol assay was applied. In group II, blood was sampled using the same protocol but applying the rapid cortisol assay. In group III, a modified sampling protocol was used, in which the additional sampling from the renal veins was dispensed with, while the rapid cortisol assay was retained. Primary endpoints were radiation exposure parameters with dose area product, fluoroscopy time, and effective dose. As secondary endpoints, procedural data including technical success, lateralization, the correlation between patient BMI and radiation exposure, and concordance of lateralization with crosssectional imaging were investigated. Furthermore, the correlation of aldosterone-cortisol ratios between the adrenal and ipsilateral renal vein was calculated to assess the benefit of sampling from the renal veins.

Results For all procedures performed in the study collective, the median dose area product was $60.01 \mathrm{~Gy}^{*} \mathrm{~cm}^{2}$ (5.71-
789.31 ), the median fluoroscopy time was 14.90 min (3.27$80.90)$, and the calculated median effective dose was $12.60 \mathrm{mSv}$ (1.20-165.76). Significant differences in radiation exposure parameters between the study subgroups could be revealed. Dose area product resulted in reductions of $57.94 \%$ after implementation of the rapid cortisol assay and a further $40.44 \%$ after revision of the sampling protocol. Fluoroscopy time was reduced by $40.48 \%$ after integration of the rapid cortisol assay and a further $40.47 \%$ after protocol refinement. Radiation doses were increased in cases of resampling (dose area product 51.31 vs. $118.11 \mathrm{~Gy}^{*} \mathrm{~cm}^{2}$, fluoroscopy time of 12.48 vs. $28.70 \mathrm{~min}$ ). A strong correlation between patient $\mathrm{BMI}$ and procedural dose area product could be found. After the introduction of the rapid cortisol assay, successive improvement of the technical success rate could be found (33.33\% in group I, $90.22 \%$ in group II and $92.11 \%$ in group III). The correlation of aldosterone-cortisol ratios between adrenal and renal veins was poor.

Conclusion The introduction of the rapid cortisol assay significantly decreased the radiation exposure and increased the technical success rate. Renal vein sampling did not provide further benefit in the evaluation of primary aldosteronism subtype and its omission resulted in a further reduction of radiation dose.

\section{Key Points:}

- The rapid cortisol assay significantly reduces the procedure-related radiation dose in adrenal vein sampling and increases the procedural technical success.

- Since additional sampling from the renal veins offers no further diagnostic benefit, a refinement of the sampling protocol can enable a further reduction of radiation dose.

- Resampling, technical unsuccessful procedures, and higher patients' BMI are associated with higher radiation exposures.

\section{Citation Format}

- Augustin A, Dalla Torre G, Fuss CT et al. Reduction of Radiation Exposure in Adrenal Vein Sampling: Impact of the Rapid Cortisol Assay. Fortschr Röntgenstr 2021; 193: 1392-1402

\section{Introduction}

Adrenal vein sampling is a minimally invasive diagnostic procedure that represents an important step in subtype determination in patients with confirmed primary aldosteronism [1, 2]. Since its results have major impact on the further therapy strategy, adrenal vein sampling represents the gold standard in this scenario and is increasingly requested by endocrinologists. Since the procedure is technically demanding, both duration of adrenal vein sampling as well as intraprocedural radiation exposure have been shown to be notably high. In addition, a high variability between institutions that perform the procedure has been demonstrated [3-5].
Among other factors, this may be due to the lack of standardization of the sampling protocol and interpretation criteria [6].

Rapid cortisol assay is an intraprocedural test, whose benefits regarding procedural success rates have already been reported [7-9]. To date, there is only one study addressing the influence of the rapid cortisol assay on radiation exposure associated with adrenal vein sampling [10]. At the same time, data comparing different sampling protocols with special regard to radiation exposure, possibly leading to an optimization of the sequence, are not yet available.

To address the need for more data, the aim of this study was to analyze the impact of the rapid cortisol assay and a modified sam- 
pling protocol on radiation exposure during adrenal vein sampling after its implementation in a larger collective of patients. In this context, we hypothesize that the rapid cortisol assay not only increases intraprocedural diagnostic confidence but may also have an impact on patients' radiation exposure in cases of uncertainty concerning sufficient selectivity and correct sampling location.

\section{Materials and methods}

\section{Study design}

Informed consent for adrenal vein sampling was obtained from each patient and approved for this retrospective study. The requirement for consent from patients to be included in this study was waived by our institutional review board (approval no.: 2020032701 ). In total, 154 patients with primary aldosteronism who underwent adrenal vein sampling in our interventional radiology division between August 2009 and March 2020 were retrospectively identified. Three patients were excluded due to the lack of data concerning radiation exposure leading to a final study cohort of 151 patients/procedures. The 151 patients included 86 men and 65 women with an average age of $52.85 \pm 10.62$ years. There was no significant difference between the study subgroups regarding patient age $\left(p_{1 / 2}=0.06, p_{2 / 3}=0.10, p_{3 / 1}=0.91\right)$. Sex distribution showed a male:female ratio of 2:1 in group I, 1.5:1 in group II and 1:1.1 in group III. All patients were biochemically diagnosed with primary aldosteronism by measuring the aldosterone to renin ratio. In 103 patients, an additional intravenous saline load test was performed for further confirmation of primary aldosteronism. All patients underwent CT or MRI prior to the intervention.

The entire cohort was divided into three subgroups according to three applied sampling protocols: Group I included patients examined in our institution under the first protocol without utilization of a rapid cortisol assay and with involvement of sampling from the renal veins: A first $10 \mathrm{ml}$ sample at the level of the infrarenal inferior vena cava (IVC), a second $10 \mathrm{ml}$ sample centrally from the left renal vein, a third $10 \mathrm{ml}$ sample from the left adrenal vein, a fourth $10 \mathrm{ml}$ sample from the right renal vein, a fifth $10 \mathrm{ml}$ sample from the right adrenal vein, a sixth $10 \mathrm{ml}$ sample at the level of the upper IVC (level above the renal veins), and a seventh $5 \mathrm{ml}$ sample at the level of the lower IVC, all of them documented by digital subtraction angiography (DSA). Group II patients received the same sampling strategy as in Group I and the rapid assay was implemented. Group III patients received a rapid cortisol assay and in their sampling protocol renal vein sampling was omitted. Group III had a first $10 \mathrm{ml}$ sample at the level of the lower IVC with radiographic documentation, a second $10 \mathrm{ml}$ sample from the left adrenal vein with verification by DSA, a third $10 \mathrm{ml}$ sample from the right adrenal vein with verification by DSA, a fourth $10 \mathrm{ml}$ sample at the level of the upper IVC illustrated by radiography, and a fifth $5 \mathrm{ml}$ sample at the level of the lower IVC documented by radiography. Case examples are given in > Fig. 1, 2 .

\section{Adrenal vein sampling procedure}

Adrenal vein sampling procedures were performed by the same operator and carried out in our local angiography suite equipped with a state-of-the-art flat-panel detector C-arm angiographic system (Axiom Artis, Siemens AG, Healthcare Sector, Forchheim, Germany) including dedicated low-dose settings and collimation filters for the acquisition of fluoroscopic, radiographic, and DSA images (CARE Body, Siemens AG, Healthcare Sector, Forchheim, Germany). The parameters were: Tube potential $70 \mathrm{kVp}$, bodyweight-adapted tube current setting ranging from 160 to $465 \mathrm{~mA}, 42 \mathrm{~cm}$ field of view, standardized system dose $0.36 \mu \mathrm{Gy}$ per pulse, pulse rate of 7.5 pulses per second, DSA frame rate of 2 frames per second, and variable and automatically adjusted prefiltering ranging from 0.2 to $0.9 \mathrm{~mm}$ during fluoroscopy and from 0.0 to $0.9 \mathrm{~mm}$ during digital acquisition (referring to the absorption of the patient entrance dose along the path of the $\mathrm{X}$-ray beam through the patient).

During the study period, changes to the systems' algorithms regarding enhanced image quality (CLEAR features) have not been performed. Concerning radiation reduction tools, the following alterations have been made within the study period: CARE vision module in March 2010, and CARE monitor/guard in April 2017.

Considering the circadian rhythm of the endocrine system, sampling was usually performed in the morning. With all patients under local anesthesia, all adrenal vein sampling procedures were conducted via an antegrade right common femoral vein approach as a sequential sampling without ACTH stimulation. After introducing a 5-F sheath (Radifocus or Destination RDC, Terumo, Tokyo), different hydrophilic catheters as well as a 0.035 " guidewire (Radifocus, Terumo, Tokyo) were used to catheterize the respective target vessel according to the protocols mentioned above. For sampling within the lower and upper IVC, a pigtail catheter (Angiodynamics, Queensbury, NY) was chosen. For sampling of the left adrenal vein, a Cobra-shaped catheter (5-F, C2, Boston Scientific, Natick, MA) was used up to a determined level of the orifice of the left renal vein and later exchanged for a catheter with a straight configuration (4-F, Glidecath, Terumo Tokyo). For sampling of the right adrenal vein, reverse-shaped selective catheters (5-F, Mikaelsson or 5-F VS2, Boston Scientific) were selected. In cases of sampling at the level of the left and right renal vein, a Cobra-shaped catheter (5-F, C2, Boston Scientific) was used.

Blood samples were collected in labelled tubes with EDTA. Tubes for the rapid cortisol assay were transferred to the endocrinology lab immediately after sampling. During the assessment of the rapid cortisol assay, the patients remained in the angiography room with the vascular sheath left in place, but the selective catheters were removed, to avoid thrombotic complications. When results of the assay indicated successful cannulation, the vascular sheath was removed and manual compression was applied, followed by a pressure bandage for hemostasis. In those cases, the assay revealed unsuccessful sampling. A second attempt at adrenal vein catheterization was performed.

In order to determine successful cannulation of the adrenal veins, the selectivity index was calculated as the ratio between cortisol concentrations from the sample of the supposed adrenal vein and a sample from the IVC. Sampling was considered as a primary technical success when bilaterally the selectivity index resulted in $\geq 2$ [11]. For assessment of the lateralization of primary 

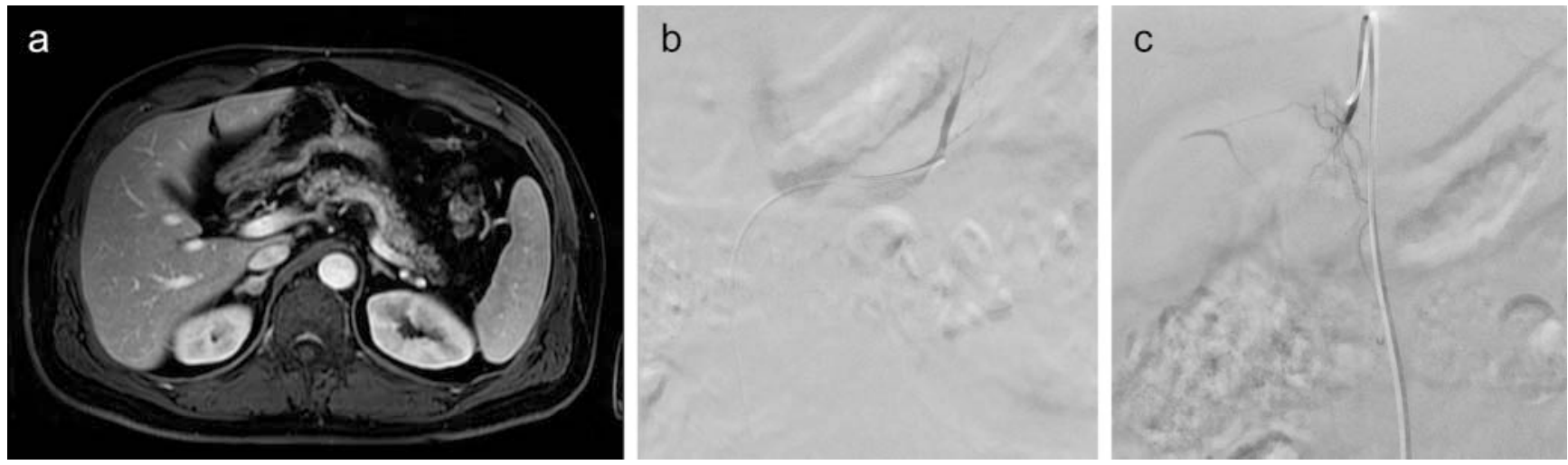

- Fig. 1 Adrenal vein sampling in a 56-year-old male patient with confirmed primary aldosteronism. a Preinterventionally performed axial abdominal MRI reveals adrenal adenoma on the right side. b Selective cannulation and venography of the left adrenal vein. $\mathbf{c}$ Cannulation of the right adrenal vein. Laboratory analysis of adrenal vein sampling showed lateralization on the ipsilateral side. Patient was successfully treated with adrenalectomy subsequently. Histopathological result showed adrenocorticoid adenoma and no proof of malignancy.

- Abb. 1 Nebennierenvenenblutentnahme bei einem 56-jährigen männlichen Patienten mit gesichertem primärem Hyperaldosteronismus. a Eine präinterventionell durchgeführte axiale abdominale MRT zeigt ein Nebennierenadenom auf der rechten Seite. b Selektive Sondierung und Venografie der linken Nebennierenvene. c Sondierung der rechten Nebennierenvene. Die Laboranalyse der Probenahme aus der Nebennierenvene ergab eine Lateralisation auf der ipsilateralen Seite. Der Patient wurde anschließend erfolgreich mittels Adrenalektomie behandelt. Das histopathologische Ergebnis ergab ein hormonaktives Adenom ohne Nachweis von Malignität.
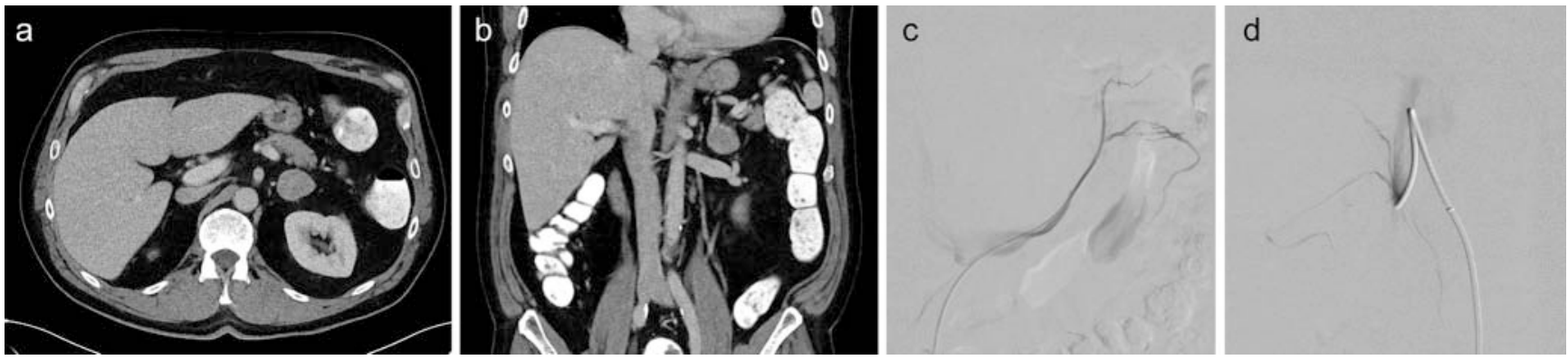

- Fig. 2 Adrenal vein sampling in a 59-year-old male patient. a, b Axial and coronal CT revealed adenoma-like adrenal mass on the left side. c, $\mathbf{d}$ Technically successful cannulation of the left and right adrenal vein confirmed by venography. Laboratory results proved unilateral origin of aldosterone hypersecretion on the left side. The patient was treated with adrenalectomy without any complications. Histopathological results revealed adrenocorticoid adenoma without proof of malignancy.

- Abb. 2 Nebennierenvenenblutentnahme bei einem 59-jährigen männlichen Patienten. a, b Die axiale und koronale CT ergaben auf der linken Seite eine noduläre Raumforderung suspekt für ein Adenom. c, d Mittels Venografie bestätigte erfolgreiche Sondierung der linken und rechten Nebennierenvene. Die Laborergebnisse belegten die unilaterale Aldosteron-Hypersekretion auf der linken Seite. Der Patient wurde komplikationslos mittels Adrenalektomie behandelt. Die histopathologischen Ergebnisse ergaben ein hormonaktives Adenom ohne Malignitätsnachweis.

aldosteronism, the lateralization index was calculated as the ratio between the aldosterone-cortisol ratio of the dominant adrenal vein by the aldosterone-cortisol ratio of the non-dominant side. A unilateral source of primary aldosteronism was considered when the lateralization index resulted in $\geq 4[12,13]$. A sampling was regarded as a secondary technical success in those cases in which first selective catheterization was insufficient, but a second resampling yielded reliable cortisol values.

\section{Laboratory measurement}

Quantitative measurement of cortisol, including the rapid cortisol assay, was performed with a solid-phase competitive chemiluminescent enzyme immunoassay (IMMULITE 2000, Siemens Health- care, Erlangen, Germany). Until September 2014, serum aldosterone was determined by Coat-a-Count radioimmunoassay (RIA, Siemens). Starting in October 2014 serum aldosterone was analyzed - after a comprehensive cross-validation - by an automated chemiluminescence immunoassay (CLIA, iSYS, Immuno Diagnostic Systems).

\section{Data evaluation and endpoint definition}

Radiologic records and patient charts were reviewed by two authors together to extract information about the procedural radiation data and the technical success as the primary and secondary endpoints of the procedure. Patient and procedure 
data were retrieved from the department's registry and the medical record system.

The primary endpoint of our study was the procedural radiation data including fluoroscopy time ( $\mathrm{min}$ ) and dose area product $\left(G y^{*} \mathrm{~cm}^{2}\right)$, which are routinely recorded during the intervention by the system's radiation dosimeter. The dose area product is the cumulative radiation dose to which a patient is exposed. Furthermore, the effective dose (mSv), representing the estimation of stochastic risk related to radiation exposure, was calculated. The effective dose, which cannot be measured directly, is commonly calculated by the multiplication of dose area product with a suitable conversion coefficient (CC), depending on the area that is exposed to $X$-rays (ED = CC * DAP) $[14,15]$. In this study, a CC of $0.21 \mathrm{mSv}$ per $\mathrm{Gy}^{*} \mathrm{~cm}^{2}$ was used as previously described, leading to an estimated calculation of ED as follows:

Effective dose $(\mathrm{mSv})=$ dose area product $\left(\mathrm{Gy}^{*} \mathrm{~cm}^{2}\right){ }^{*} 0.21(\mathrm{mSV} /$ $\left.\mathrm{Gy}^{*} \mathrm{~cm}^{2}\right)[16]$.

As secondary endpoints, technical success, correlation of the aldosterone-cortisol ratio between the adrenal and renal veins, the correlation between the patient's BMI and radiation exposure, and in cases of technical success, lateralization, and concordance with cross-sectional imaging, were investigated. In this context, overall technical success was defined as the diagnostic outcome of primary technical success and secondary technical success after resampling.

\section{Statistical analysis}

Descriptive data were presented as means \pm standard deviation for normally distributed variables or medians with ranges for non-normalized variables, if appropriate. Categorical data were expressed as counts and percentages with $\mathrm{n}(\%)$. With regard to the assessment of normality, the Anderson-Darling test was used, rejecting the hypothesis of normality when the p-value is less or equal to 0.05 . The Mann-Whitney U test and Student's t-test were used for comparison of the described subgroups. Correlation analysis of ordinal and metrical data was performed with the test according to Spearman for non-normalized variables. For all evaluations, a p-value less than 0.05 was considered to indicate significant differences. Statistical analysis and the evaluation of the data were performed with a specialized computer algorithm (Microsoft Excel V1908 and RStudio 1.2.5033).

\section{Results}

Patient characteristics and procedural data of the entire study cohort are presented in $\boldsymbol{\nabla}$ Table $\mathbf{1}$. In total, data of 151 patients and adrenal vein sampling procedures were evaluated. The overall technical success was $82.78 \%$. The rapid cortisol test, which was introduced in March 2013, was applied in 130/151 cases $(86.09 \%)$. Technical success was $33.33 \%$ in group I, $90.22 \%$ in group II, and $92.11 \%$ in group III. Based on the results of the rapid cortisol assay, revealing insufficient selective cannulation, a second sampling was performed in 27 cases. In 22 of those 27 cases $(81.48 \%)$, secondary technical success was achieved by resampling. Within the study subgroups, the resampling, follow-
- Table 1 Patient and procedural data.

- Tab.1 Demografische und prozedurale Parameter.

\begin{tabular}{|c|c|c|}
\hline mean age (years) & & $52.85 \pm 10.62$ \\
\hline male:female ratio & & $86: 65$ \\
\hline \multirow[t]{2}{*}{ median BMI (kg/m²) } & & $29.03(17.60-51.28)$ \\
\hline & $\%$ & $\mathbf{n}$ \\
\hline overall procedures (n) & & 151 \\
\hline overall technical success (\%) & 82.78 & $125 / 151$ \\
\hline group I & 33.33 & $7 / 21$ \\
\hline group II & 90.22 & $83 / 92$ \\
\hline group III & 92.11 & $35 / 38$ \\
\hline RCA (\%) & 86.09 & $130 / 151$ \\
\hline resampling (n) & 17.88 & $27 / 151$ \\
\hline success after resampling (n) & 81.48 & $22 / 27$ \\
\hline renal vein sampling & 74.83 & $113 / 151$ \\
\hline overall median DAP $\left(\mathrm{Gy}^{*} \mathrm{~cm}^{2}\right)$ & & $60.01(5.71-789.31)$ \\
\hline overall median FT (min) & & $14.90(3.27-80.90)$ \\
\hline overall median ED (mSv) & & $12.60(1.20-165.76)$ \\
\hline right-sided lateralization & 26.40 & $33 / 125$ \\
\hline left-sided lateralization & 33.60 & $42 / 125$ \\
\hline no lateralization & 40.00 & $50 / 125$ \\
\hline $\begin{array}{l}\text { lateralization concordant to } \\
\text { imaging }\end{array}$ & 72.80 & $91 / 125$ \\
\hline no concordance & 24.20 & $34 / 125$ \\
\hline
\end{tabular}

$\mathrm{BMI}=$ body mass index; $\mathrm{RCA}=$ rapid cortisol assay, $\mathrm{DAP}=$ dose area product; $\mathrm{FT}=$ fluoroscopy time; $\mathrm{ED}=$ effective dose.

$\mathrm{BMI}=$ Body-Mass-Index; RCA = Kortison-Schnelltest; DAP = Dosis-

Flächen-Produkt; FT = Durchleuchtungszeit; ED = effektive Dosis.

ing negative results of the rapid cortisol assay, resulted in secondary technical success in $21.74 \%$ of the procedures in group II and in $5.23 \%$ in group III. In 2019, adrenal vein sampling protocols were revised and sampling from the renal veins was no longer performed. In total, renal vein sampling was part of the sampling protocol in $113 / 151$ cases $(74.83 \%)$.

The median dose area product for all procedures was $60.01 \mathrm{~Gy}^{*} \mathrm{~cm}^{2}$ (5.71-789.31). The median fluoroscopy time was $14.90 \mathrm{~min}$, ranging from values between 3.27 and $80.90 \mathrm{~min}$. The calculated median effective dose was 12.60 mSv (1.20165.76). Statistically significant differences regarding radiation exposure parameters were found between all subgroups, in favor of subgroups II and III ( $\triangleright$ Fig. 3). Differences in dose area product and fluoroscopy between groups I and II, characterized by the introduction of the rapid assay, were statistically significant with a reduction in dose area product of $57.94 \%(p<0.001)$ and fluoroscopy time of $40.48 \%(p=0.026)$. Excluding renal vein sampling from the protocol resulted in highly significant differences of 

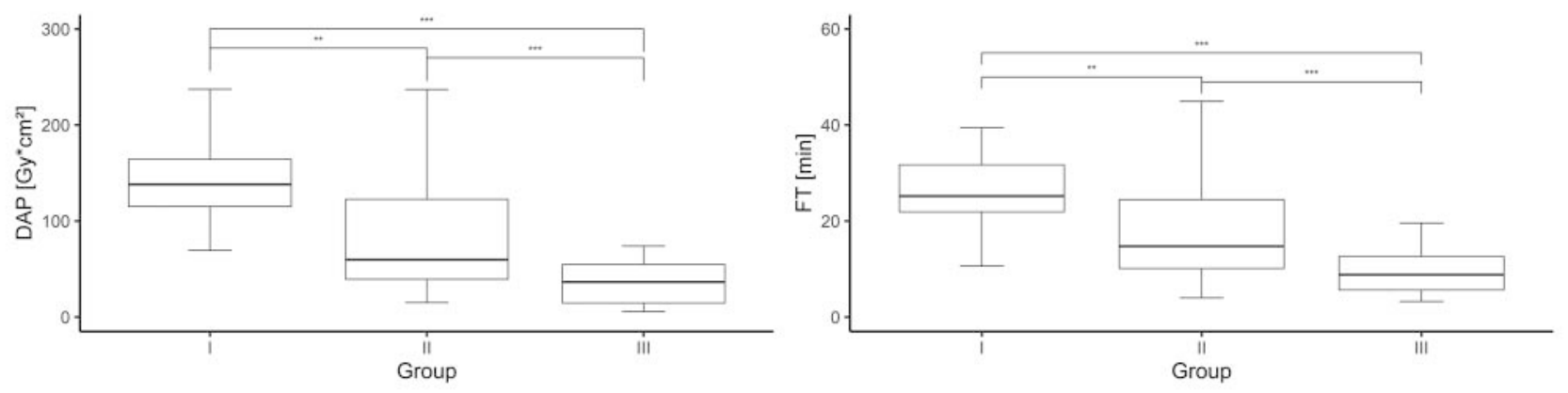

- Fig. 3 Dose area product $\left(\mathrm{Gy}^{*} \mathrm{~cm} 2\right)$ and fluoroscopy time $(\mathrm{min})$ of the three study subgroups. Group I: Without the rapid cortisol assay, including renal vein sampling; group II: with rapid cortisol assay, including renal vein sampling; group III: with rapid cortisol assay, without renal vein sampling.

- Abb. 3 Dosis-Flächen-Produkt $\left(G{ }^{*} \mathrm{~cm}^{2}\right)$ und Durchleuchtungszeit $(\mathrm{min})$ der 3 Studiengruppen. Gruppe I: ohne Kortison-Schnelltest, einschließlich der Abnahme aus den Nierenvenen; Gruppe II: mit Kortison-Schnelltest, einschließlich der Abnahme aus den Nierenvenen; Gruppe III: mit KortisonSchnelltest, ohne Abnahme aus den Nierenvenen.

- Table 2 Results of subgroup analysis regarding radiation exposure.

- Tab. 2 Ergebnisse der Subgruppenanalyse in Bezug auf die Strahlenbelastung.

\begin{tabular}{|c|c|c|c|c|c|c|c|}
\hline group & $\mathbf{n}$ & $\%$ & age (years) & BMI $\left(\mathrm{kg} / \mathrm{m}^{2}\right)$ & $\operatorname{DAP}\left(\mathrm{Gy}^{*} \mathrm{~cm}^{2}\right)$ & FT (min) & ED (mSv) \\
\hline I & 21 & 13.91 & $48.90 \pm 9.29$ & $29.67(18.44-42.87)$ & $146.02(9.15-789.31)$ & $25.20(4.50-39.40)$ & $30.66(1.92-165.76)$ \\
\hline II & 92 & 60.93 & $53.41 \pm 10.07$ & $28.76(18.52-48.96)$ & $61.42(15.04-481.08)$ & $15.00(4.00-80.90)$ & $12.90(3.16-101.03)$ \\
\hline III & 38 & 25.17 & $53.68 \pm 12.28$ & $29.91(17.60-51.28)$ & $36.58(5.71-413.76)$ & $8.93(3.27-75.20)$ & $7.86(1.20-86.89)$ \\
\hline
\end{tabular}

Group I: Without RCA, including renal vein sampling; group II: with RCA, including renal vein sampling; group III: with RCA, without renal vein sampling. $\mathrm{BMI}=$ body mass index; $\mathrm{DAP}=$ dose area product; $\mathrm{FT}=$ fluoroscopy time; $\mathrm{ED}=$ effective dose.

Gruppe I: ohne RCA, einschließlich Abnahme aus den Nierenvenen; Gruppe II: mit RCA, einschließlich Abnahme aus Nierenvenen; Gruppe III: mit RCA, ohne Abnahme aus den Nierenvenen. BMI = Body-Mass-Index; DAP= Dosis-Flächen-Produkt; FT = Durchleuchtungszeit; ED = effektive Dosis.

radiation exposure in groups II and III ( $p<0.001$ for both dose area product and fluoroscopy time) with a dose area product reduction of $40.44 \%$ and fluoroscopy time reduction of $40.47 \%$. Corresponding results are illustrated in $>$ Table 2.

Analysis of correlation between a patient's sex and radiation exposure resulted in significantly lower values of dose area product in female patients (88.00 vs. $38.82 \mathrm{~Gy}^{*} \mathrm{~cm}^{2}, \mathrm{p}<0.001$ ), whereas fluoroscopy time showed minor, but no statistically significant reduction in female patients (15.44 vs. $14.60 \mathrm{~min}$, $p=0.256)$. A significant correlation between patient age and radiation exposure was not found. In this context, a rho-value of $0.066(p=0.420)$ was calculated for the dose area product and a rho-value of $0.043(p=0.570$ ) was determined for fluoroscopy time. Resampling significantly increased radiation exposure with a median dose area product of 118.11 vs. $51.74 \mathrm{~Gy}^{*} \mathrm{~cm}^{2}$ $(p<0.001)$ and a median fluoroscopy time of $28.70 \mathrm{vs.} 12.48 \mathrm{~min}$ $(p<0.001)(\triangleright$ Fig. 4). In technically successful cases, radiation exposure was significantly decreased, leading to a dose area product of 51.34 vs. $131.20 \mathrm{~Gy}^{*} \mathrm{~cm}^{2}(\mathrm{p}<0.001)$ and fluoroscopy time of 12.57 vs. $28.55 \mathrm{~min}(\mathrm{p}<0.001)$. Dose area product and fluorosco- py time showed a strong correlation (rho-value $=0.601$; $\mathrm{p}<0.001)$.

The median body mass index (BMI) of the whole patient cohort was $29.03 \mathrm{~kg} / \mathrm{m}^{2}$ (range 17.60-51.28) and revealed no significant differences between male and female patients (29.27 vs. 28.67; $p=0.107)$. However, bodyweight between male and female patients differed significantly (95 vs. $77 \mathrm{~kg} ; \mathrm{p}<0.001)$ as well as body height ( 179.50 vs. 166.00; $p<0.001)$. Differences in median $\mathrm{BMI}$ between the subgroups were also not significant $\left(\mathrm{p}_{1 / 2}\right.$ $\left.=0.509 ; p_{2 / 3}=0.279 ; p_{3 / 1}=0.887\right)$. However, a significant positive correlation between $\mathrm{BMI}$ and dose area product could be detected (rho-value $0.502 ; \mathrm{p}<0.001$ ). In contrast, a relevant correlation between a patient's BMI and fluoroscopy time was not found (rho-value -0.003; $p=0.399$ ). A comparison of obese patients $(\mathrm{BMI} \geq 30)$ and patients with a $\mathrm{BMI}<30$ resulted in highly significant differences in dose area product (112.70 vs. $46.55 \mathrm{~Gy}^{*} \mathrm{~cm}^{2}$; $p<0.001)$, while a significant difference in fluoroscopy time could not be found ( 15.44 vs. $12.83 \mathrm{~min} ; \mathrm{p}=0.592$ ).

Technical success failed due to unsuccessful sampling on the right side in 13 cases, on the left side in four cases, and bilaterally 

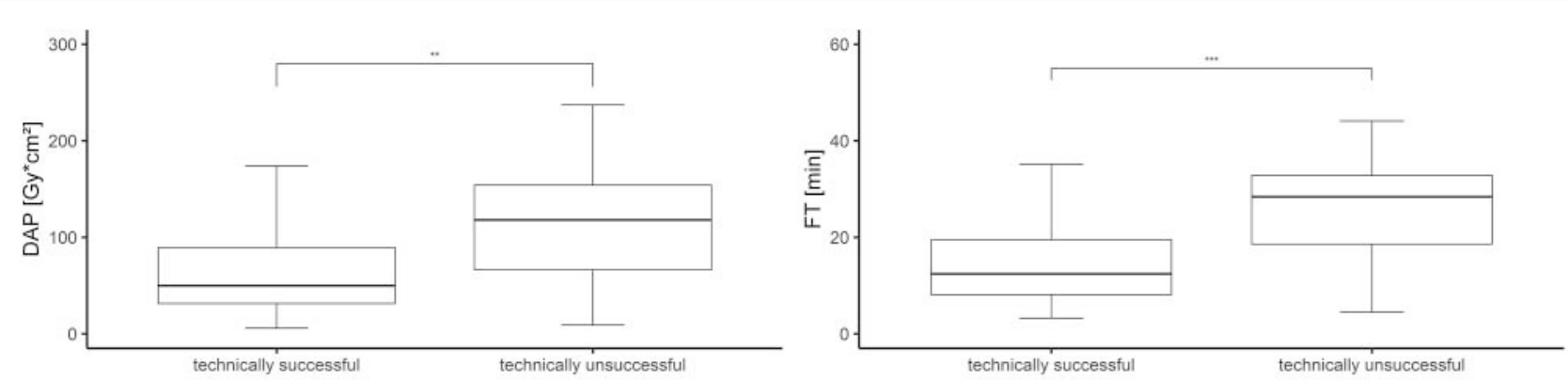

- Fig. 4 Comparison of median dose area product $\left(G y^{*} \mathrm{~cm} 2\right)$ and fluoroscopy time $(\mathrm{min})$ in technically successful and unsuccessful procedures.

- Abb.4 Dosis-Flächen-Produkt $\left(\mathrm{Gy}^{*} \mathrm{~cm}^{2}\right)$ und Durchleuchtungszeit ( $\left.\mathrm{min}\right)$ bei technisch erfolgreichen und nichterfolgreichen Interventionen.

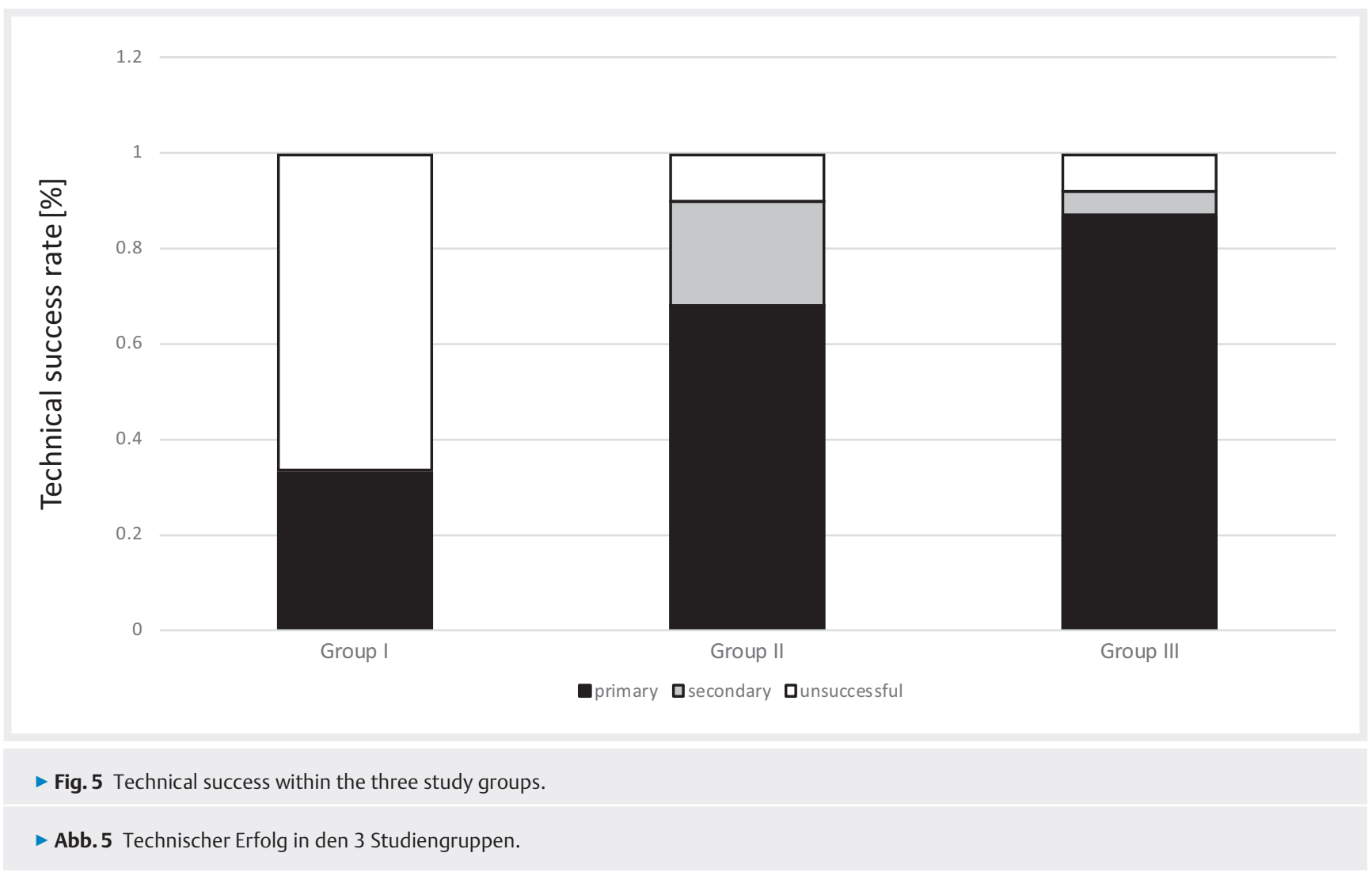

in nine cases. Results of the Chi-Square Test showed a strong correlation between the side of sampling and the technical success in terms of a significantly higher rate of unsuccessful sampling due to failure on the right side $(p<0.001)$. Lateralization of aldosterone excess was confirmed in 75 of 125 cases (60.00\%) and revealed a left-sided hormone excess in 42 (33.60\%) and rightsided in 33 (26.40\%) technically successful procedures. In 50 cases $(40.00 \%)$, adrenal vein sampling did not reveal unilateral hypersecretion with subsequent diagnosis of bilateral adrenal hyperplasia.

In 91/125 cases ( $72.80 \%$ ), analysis of preinterventional CT and MRI was concordant with adrenal vein sampling with an adrenal mass on the side of hormone excess or no adenoma in cases of bilateral aldosteronism. In 16 cases (12.80\%), the presence of a unilateral adenoma on imaging was not associated with the confirmed diagnosis of unilateral aldosterone overproduction by successful catheterization. One case resulted in lateralization on the left side, while adenoma was detected on the contralateral side, which was confirmed histologically. In 17 cases (13.60\%), unilateral origin of aldosterone excess was found, although an adenoma had not been identified on MRI or CT ( $\triangleright$ Fig. 5).

Sampling from the renal veins was performed in 113 cases (74.83\%). Spearman's correlation analysis revealed a moderate association between aldosterone-cortisol values of the left adrenal vein and the left renal vein $(r=0.43 ; p<0.05)$. In contrast, the correlation of the renal and adrenal aldosterone-cortisol ratio on 


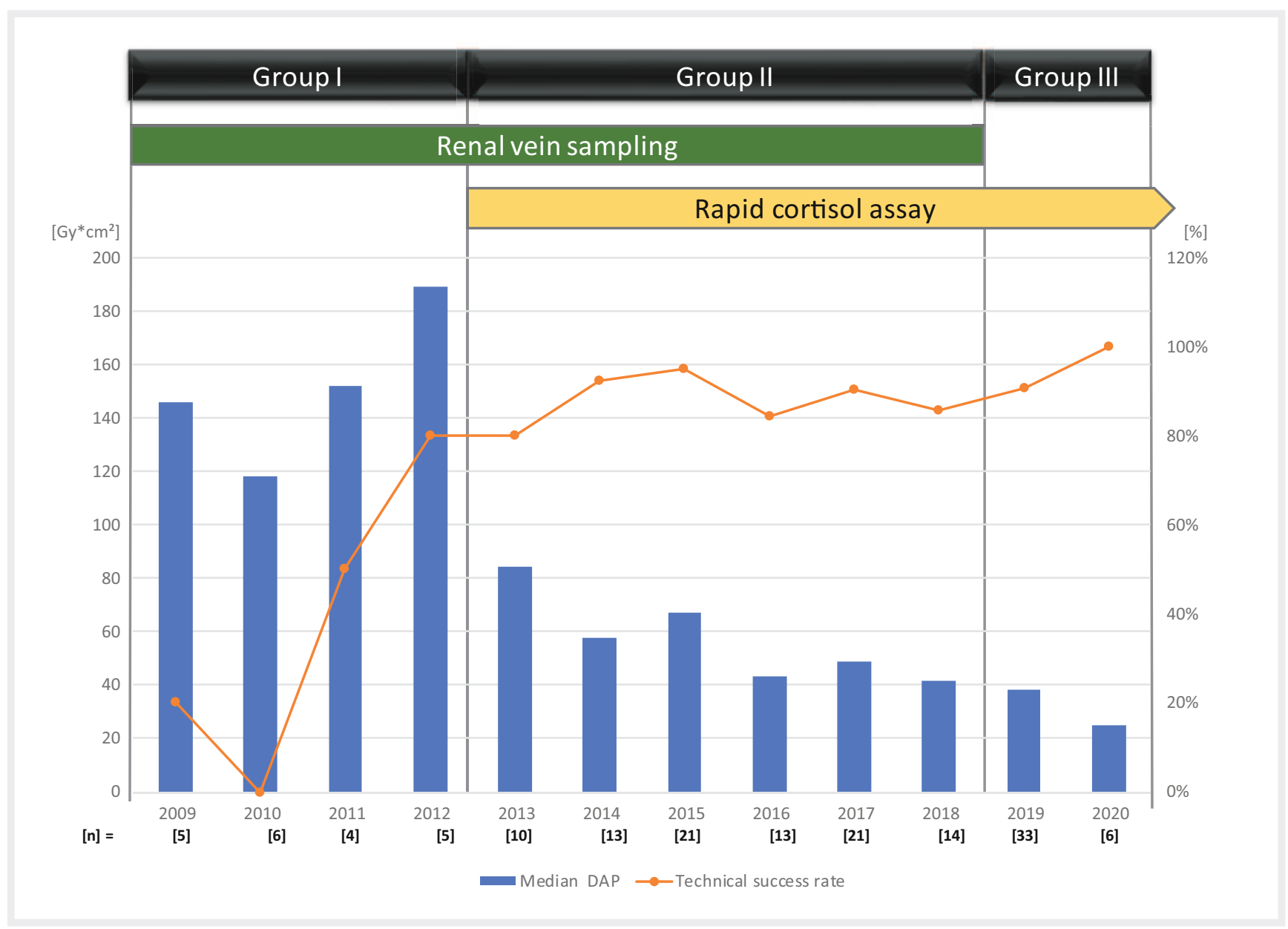

$\checkmark$ Fig. 6 Development of dose area product (DAP, $\mathrm{Gy}^{*} \mathrm{~cm}^{2}$ ) values in adrenal vein sampling over the time within the study period. Furthermore, development of technical success of adrenal vein sampling per year and characterization of study subgroups concerning the sampling protocol are shown.

- Abb. 6 Entwicklung des Dosis-Flächen-Produkts (DAP, $\mathrm{Gy}^{*} \mathrm{~cm}^{2}$ ) bei der selektiven Nebennierenvenenblutentnahmen innerhalb des Studienzeitraums sowie der technische Erfolg mit Kennzeichnung der jeweiligen Studienuntergruppen.

the right side proved to be minor and not significant $(r=0.16$; $p=0.172$ ). Over the study period of 11 years, a successive reduction of dose area product and fluoroscopy time could be observed, while at the same time the technical success rate increased ( $\triangleright$ Fig. 6).

\section{Discussion}

Fluoroscopy-guided abdominal interventions like adrenal vein sampling are generally considered to be radiation-intensive procedures $[3,17]$. The importance of optimizing radiation exposure in adrenal vein sampling is additionally emphasized by the fact that patients undergoing this procedure are usually younger than those receiving other endovascular procedures. Therefore, the mean age of the patients included in this study was 52.9 years.

In this retrospective study, we evaluated the impact of the rapid cortisol assay as well as the modification of the adrenal vein sampling protocol and its impact on radiation exposure.
Due to the fact that all procedures were performed by the same interventional radiologist, biases due to differing preferences in procedure strategy and protocol settings did not play a major role, even if the other staff members changed over time. Furthermore, the same flat-panel detector C-arm angiography system was used during the whole study period, thus hardwaredependent influences can be neglected. The number of included procedures is a strength of the study, which is attributed to the fact that our hospital is one of the national referral centers for primary aldosteronism.

Implementation of the rapid cortisol test for intraprocedural verification of correct sampling locations resulted in a significant reduction of radiation doses. Those results are consistent with one study, addressing this special topic and proving increased success rates while at the same time minimizing radiation exposure during adrenal vein sampling [10]. Presumably, this is caused by the increased diagnostic confidence gained from the periprocedural rapid cortisol assay. In adrenal vein sampling without the test, the interventionalist tends to use longer fluoroscopy times and more frequent acquisition of DSA series in order to verify the 
correct sampling site. As a powerful tool, the rapid cortisol assay offered prompt feedback concerning the technical success of procedures and made it possible to bail out in cases in which the first attempt at diagnostic sampling failed. Therefore, repeated procedures may be avoided, which will inevitably lead to a reduction of costs, a decrease of procedure-related risks, accelerated diagnostics, and a faster initiation of therapy, although those aspects were not the subject of the presented study. The certainty of being able to perform repeated sampling during the same procedure in the event of an inadequate result may thus have a relevant impact on the procedural strategy of interventional radiologists.

In our study collective, resampling was performed in 27 of 151 proedures, with secondary technical success in 22 procedures $(81.48 \%)$, increasing the overall technical success by $14.57 \%$. Even though execution of resampling was associated with increased radiation, this additional radiation exposure is lower than the doses associated with a repeated procedure and is therefore justifiable.

A previously performed multicenter study analyzed the radiation doses during adrenal vein sampling procedures in different centers and revealed a high variability between the performing institutions [3]. In this context, the dose area product of the respective centers ranged between 16 and $147 \mathrm{~Gy}^{*} \mathrm{~cm}^{2}$, fluoroscopy time between 3.2 and 29 min and ED between 16 and $27 \mathrm{mSv}$. Taking those results as a reference, the initial radiation exposure values in our study collective (Group I) are comparable to those with the highest dose area product, fluoroscopy time, and effective dose, whereas, after implementing all described revisions of the protocol of the procedures (Group III), radiation dose parameters similar to those in the lower third of the evaluated parameters were achieved.

In contrast to previous studies, we additionally evaluated the habitus of the patients that underwent adrenal vein sampling. The radiation dose is highly influenced by the patient's physical constitution with higher radiation doses in obese patients $[18,19]$. Accordingly, our results revealed a significant correlation between the patient's BMI and procedural dose area product. Furthermore, significant differences in dose area product were found between patients with obesity and those without. Influences on the subgroup results based on unequal BMI values could be excluded. Furthermore, the higher dose area product in overweight patients was not attributed to longer fluoroscopy times. Interestingly, with comparable fluoroscopy times, dose area product values between male and female patients were significantly different. However, the body height and weight of the male patients was significantly higher, thus not only BMI but also patient size might be predictors for the resulting dose area product [20].

As a further endpoint of the presented study, procedural success rates increased after implementation of the rapid cortisol assay. This fact shows high concordance with other previously performed studies, proving an increase in technical success, especially in centers with only little experience with adrenal vein sampling. With a remarkably high number of resamplings, Betz et al. [21] reported an improvement of the technical success rate of $30 \%$. In a moderate-sized patient collective, Rossi et al. [8] achieved a technical success rate of $92 \%$ after implementation of the assay compared to a historical series without the rapid cortisol assay with a success rate of $76 \%$. Another study reported an increase of the success rate of $26 \%$, comparing 30 conventional adrenal vein sampling procedures with 30 procedures after the establishment of the rapid cortisol assay [7].

Beside the rapid cortisol assay, a significant reduction in radiation dose was observed after revising the sampling protocol in terms of omitting sampling from the renal veins. Prior to this, renal vein sampling had been performed, since venous drainage of adrenal glands had also been described for the right side, albeit to a lesser extent than on the left [22]. Various investigations have been performed in the past with the goal of assessing incomplete, but complementary adrenal vein sampling data with special regard to a reliable determination of the primary aldosteronism subtype. In this context, one secondary endpoint of the presented study was evaluating the value of additional blood sampling from the renal veins. Hypothetically, in the case of a strong correlation of aldosterone and cortisol levels in the renal and adrenal vein, the technically less challenging blood sampling from the renal veins could serve as an alternative in cases of unsuccessful adrenal sampling. Our data revealed a moderate correlation between aldosterone and cortisol quotients on the left but only a poor association on the right side. This result seems to be reasonable and consistent based on anatomical aspects of the adrenal veins. The left adrenal vein directly drains into the ipsilateral renal vein. Therefore, the level of adrenocortical hormones from samples of the renal vein can be expected to be higher due to fewer dilution effects. On the right side, a direct anatomical connection between the renal and adrenal vein does not exist. Therefore, results are distinctly affected by dilution. Even if the finding or exclusion of pathologically elevated aldosterone levels on the left side might help to predict the primary aldosteronism subtype, results of other studies indicated inadequate sensitivity of incomplete adrenal vein sampling data in terms of identifying patients suitable for surgery [23]. We, therefore, consider sampling from the renal veins to be non-diagnostic and neglectable.

In our study setting, the rapid cortisol assay was performed in the hospital's laboratory, whereas other institutions are already able to carry out the assay in the local angiography suite with a point-of-care system [9]. This might be certainly advantageous because of the potentially faster processes, direct feedback, and the possibly reduced risk of errors in sample identification. Therefore, such a setting seems to be preferable in centers where adrenal vein samplings are frequently performed.

With almost a third of the successful procedures leading to discordant results with CT and MRI, our results revealed similar unreliability in subtype diagnostics based on cross-sectional imaging alone, when compared to other studies [24, 25]. In this scenario, the failed assessment of a hormonally inactive adenoma as the source of hormonal excess may lead to unnecessary surgery or, in the worst case, to adrenalectomy on the incorrect side. On the other hand, an unproven unilateral subtype of primary aldosteronism based on CT and MRI might be insufficiently treated with mineralocorticoid antagonist therapy, frequently failing to normalize blood pressure [26].

The lack of standardization of data interpretation and solid diagnostic criteria, especially due to different SI and LI values, 
may lead to different results in the same scenarios and thus constitutes a limitation regarding the procedural diagnostic reliability $[27,28]$. This restriction must be taken into account when interpreting results of adrenal vein sampling. It emphasizes the importance of making the final diagnosis of primary aldosteronism subtype considering all available individual findings and aspects.

The limitations of this study include the retrospective, singlecenter, and non-randomized study design. Moreover, the impact of the rapid cortisol assay on the technical success rate as well as radiation dose could be overestimated and partially be the wellknown side effect of the learning curve of interventionalists [29]. Nevertheless, Jakobsson et al. [30] found a plateau of satisfactory results after performing approximately 36 interventions and those results are likely to be transferable with respect to radiation protection habits. At the time of the study start, the interventional radiologist performing the procedure had 12 years of experience with interventional procedures, including adrenal vein sampling. This might also be reflected by the timeline representing the technical success over the years ( $\triangleright$ Fig. 6), proving a plateau of technical success at $80 \%$ reached in 2012, which was again slightly improved after the introduction of the cortisol assay. Radiation exposure parameters, on the other hand, revealed a successive increase within the first study years, but significantly reduced after implementation of the rapid cortisol assay. Therefore, the overall influence of the learning curve on radiation exposure was minor as compared to the implementation of the rapid cortisol assay.

Furthermore, alterations of the image-quality and dose-saving tools provided by the manufacturer might have a relevant impact on radiation dose, regardless of the procedural protocol [31]. Nevertheless, we retrospectively assessed that during the study period significant changes in the dose reduction portfolio have not been performed. The only feature that was added during the study period and that could possibly have an influence on radiation exposure was the CARE vision module, which was implemented in March 2010. However, a significant change in radiation doses was not found during this period. Since this alteration had been performed at the start of the study period, we do not expect a relevant impact on the analyzed data.

Another limitation is represented by the calculation of the effective dose. As a quantitative parameter for the stochastic risk associated with radiation exposure, it cannot be measured directly but is calculated by multiplication of the dose area product with the appropriate conversion coefficients, considering factors like tube voltage, field position, filtration, and patient characteristics $[32,33]$. In this study, effective dose values were calculated using a single correlation coefficient suggested by the literature, considering neither the patient's gender nor bodyweight [16]. We are aware that this can only serve as an approximate estimation. Nevertheless, since this study addresses the differences in radiation exposure between the different subgroups rather than the determination of absolute values, this simplified process seems to be justified in our opinion.

In conclusion, implementation of the rapid cortisol assay in adrenal vein sampling leads to a significant reduction of radiation exposure in patients while at the same time increasing the proce- dural technical success and preventing reintervention. Since additional sampling from the renal veins does not offer additional diagnostic value, these sampling locations were omitted which led to a further radiation reduction.

\section{Conflict of Interest}

The authors declare that they have no conflict of interest.

\section{References}

[1] Rossi GP, Auchus R], Brown M et al. An expert consensus statement on use of adrenal vein sampling for the subtyping of primary aldosteronism. Hypertension 2014; 63 (1): 151-160

[2] Funder JW, Carey RM, Mantero F et al. The Management of Primary Aldosteronism: Case Detection, Diagnosis, and Treatment: An Endocrine Society Clinical Practice Guideline. J Clin Endocrinol Metab 2016; 101 (5): 1889-1916

[3] Fuss CT, Treitl M, Rayes N et al. Radiation Exposure of Adrenal Vein Sampling - a German Multicenter Study. Eur J Endocrinol 2018; 179 (4): 261-267

[4] Stewart PM, Allolio B. Adrenal vein sampling for Primary Aldosteronism: time for a reality check. Clin Endocrinol (Oxf) 2010; 72 (2): 146-148

[5] Vonend O, Ockenfels N, Gao X et al. Adrenal venous sampling: evaluation of the German Conn's registry. Hypertension 2011; 57 (5): 990-995

[6] Monticone S, Viola A, Rossato D et al. Adrenal vein sampling in primary aldosteronism: towards a standardised protocol. Lancet Diabetes Endocrinol 2015; 3 (4): 296-303

[7] Auchus RJ, Michaelis C, Wians FH Jr et al. Rapid cortisol assays improve the success rate of adrenal vein sampling for primary aldosteronism. Ann Surg 2009; 249 (2): 318-321

[8] Rossi E, Regolisti G, Perazzoli F et al. Intraprocedural cortisol measurement increases adrenal vein sampling success rate in primary aldosteronism. Am J Hypertens 2011; 24 (12): 1280-1285

[9] Mengozzi G, Rossato D, Bertello $C$ et al. Rapid cortisol assay during adrenal vein sampling in patients with primary aldosteronism. Clin Chem 2007; 53 (11): 1968-1971

[10] Page MM, Taranto M, Ramsay D et al. Improved technical success and radiation safety of adrenal vein sampling using rapid, semi-quantitative point-of-care cortisol measurement. Ann Clin Biochem 2018; 55 (5): 588-592

[11] Rossi GP, Sacchetto A, Chiesura-Corona M et al. Identification of the etiology of primary aldosteronism with adrenal vein sampling in patients with equivocal computed tomography and magnetic resonance findings: results in 104 consecutive cases. J Clin Endocrinol Metab 2001; 86 (3): 1083-1090

[12] Magill SB, Raff H, Shaker JL et al. Comparison of adrenal vein sampling and computed tomography in the differentiation of primary aldosteronism. J Clin Endocrinol Metab 2001; 86 (3): 1066-1071

[13] Rossi GP. New concepts in adrenal vein sampling for aldosterone in the diagnosis of primary aldosteronism. Curr Hypertens Rep 2007; 9 (2): 90-97

[14] Miller DL, Balter S, Dixon RG et al. Quality improvement guidelines for recording patient radiation dose in the medical record for fluoroscopically guided procedures. J Vasc Interv Radiol 2012; 23 (1): 11-18

[15] Smans K, Struelens L, Hoornaert MT et al. A study of the correlation between dose area product and effective dose in vascular radiology. Radiat Prot Dosimetry 2008; 130 (3): 300-308

[16] Le Heron JC. Estimation of effective dose to the patient during medical $x$-ray examinations from measurements of the dose-area product. Phys Med Biol 1992; 37 (11): 2117-2126 
[17] Sailer AM, Paulis L, Vergoossen L et al. Real-Time Patient and Staff Radiation Dose Monitoring in IR Practice. Cardiovasc Intervent Radiol 2017; 40 (3): 421-429

[18] Ector ], Dragusin O, Adriaenssens B et al. Obesity is a major determinant of radiation dose in patients undergoing pulmonary vein isolation for atrial fibrillation. J Am Coll Cardiol 2007; 50 (3): 234-242

[19] Lacayo EA, Khera SS, Spies JB. Impact of Patient and Procedure-Related Factors on Radiation Exposure from Uterine Artery Embolization. Cardiovasc Intervent Radiol 2020; 43 (1): 120-126

[20] Chida K, Ohno T, Kakizaki S et al. Radiation dose to the pediatric cardiac catheterization and intervention patient. Am J Roentgenol 2010; 195 (5): 1175-1179

[21] Betz M], Degenhart C, Fischer E et al. Adrenal vein sampling using rapid cortisol assays in primary aldosteronism is useful in centers with low success rates. Eur J Endocrinol 2011; 165 (2): 301-306

[22] Daunt N. Adrenal vein sampling: how to make it quick, easy, and successful. Radiographics 2005; 25 (Suppl. 1): S143-S158

[23] Wang TS, Kline G, Yen TW et al. A Multi-institutional Comparison of Adrenal Venous Sampling in Patients with Primary Aldosteronism: Caution Advised if Successful Bilateral Adrenal Vein Sampling is Not Achieved. World J Surg 2018; 42 (2): 466-472

[24] Kempers M], Lenders JW, van Outheusden L et al. Systematic review: diagnostic procedures to differentiate unilateral from bilateral adrenal abnormality in primary aldosteronism. Ann Intern Med 2009; 151 (5): 329-337

[25] Raman SP, Lessne M, Kawamoto S et al. Diagnostic performance of multidetector computed tomography in distinguishing unilateral from bilateral abnormalities in primary hyperaldosteronism: comparison of multidetector computed tomography with adrenal vein sampling. J Comput Assist Tomogr 2015; 39 (3): 414-418

[26] Milliez P, Girerd X, Plouin PF et al. Evidence for an increased rate of cardiovascular events in patients with primary aldosteronism. J Am Coll Cardiol 2005; 45 (8): 1243-1248

[27] Mulatero P, Bertello C, Sukor N et al. Impact of different diagnostic criteria during adrenal vein sampling on reproducibility of subtype diagnosis in patients with primary aldosteronism. Hypertension 2010; 55 (3): 667-673

[28] Rossitto G, Amar L, Azizi M et al. Subtyping of Primary Aldosteronism in the AVIS-2 Study: Assessment of Selectivity and Lateralization. J Clin Endocrinol Metab 2019; 105 (6): 2042-2052

[29] Andrews RT, Brown PH. Uterine arterial embolization: factors influencing patient radiation exposure. Radiology 2000; 217 (3): 713-722

[30] Jakobsson H, Farmaki K, Sakinis A et al. Adrenal venous sampling: the learning curve of a single interventionalist with 282 consecutive procedures. Diagn Interv Radiol 2018; 24 (2): 89-93

[31] Verstandig AG, Shamieh B, Shraibman V et al. Radiation dose reduction in fluoroscopic procedures: left varicocele embolization as a model. Eur Radiol 2015; 25 (6): 1639-1645

[32] Gosch D, Gosch K, Kahn T. [Conversion coefficients for estimation of effective dose to patients from dose area product during fluoroscopy x-ray examinations]. Rofo 2007; 179 (10): 1035-1042

[33] Mahesh M. Fluoroscopy: patient radiation exposure issues. Radiographics 2001; 21 (4): 1033-1045 